\title{
HUBUNGAN INTENSITAS BELAJAR DENGAN HASIL BELAJAR PPKN SISWA KELAS IV SDN SEKECAMATAN KEBUMEN TAHUN AJARAN 2020/2021
}

\author{
Universitas Sebelas Maret \\ erlyndakusuma@student.uns.ac.id
}

Erlynda Ayu Kusumawati ${ }^{1}$, Ngatman ${ }^{2}$, Wahyudi $^{3}$

\section{Article History}

accepted 30/8/2021

approved 30/9/2021

published 30/10/2021

\begin{abstract}
The study aimed to examine significant and positive correlation between learning intensity and Pancasila and Civic Education learning outcomes to fourth grade students and to determine the contribution of learning intensity on Pancasila and Civic Education learning outcomes to fourth grade students of public elementary schools in Kebumen sub-district in academic year of 2020/2021. It was a correlational quantitative study. The population were 1400 fourth grade students while the samples were 347 fourth grade students. Data collection techniques used questionnaires and tests. The prerequisite test used linearity and normality tests. Data analysis used simple correlation test and adjusted $R$ square. It concludes that there was positive and significant correlation between learning intensity and Pancasila and Civic Education learning outcomes to fourth grade students of public elementary schools in Kebumen sub-district. 0.371 was considered a moderate correlation and learning intensity contributed $13.7 \%$ on Pancasila and Civic Education learning outcomes.
\end{abstract}

Keywords: learning intensity, learning outcomes, Pancasila and Civic Education

\begin{abstract}
Abstrak
Penelitian ini bertujuan untuk membuktikan adanya hubungan positif yang signifikan antara intensitas belajar dengan hasil belajar PPKn siswa kelas IV SD dan menghitung besarnya sumbangan intensitas belajar dengan hasil belajar PPKn siswa kelas IV SDN se-Kecamatan Kebumen tahun ajaran 2020/2021. Penelitian ini merupakan penelitian kuantitatif korelasional. Populasinya 1400 siswa dan sampelnya 347 siswa. Teknik pengumpulan data dengan tes dan angket. Uji prasyarat meggunakan uji normalitas dan linieritas. Analisis data penelitian ini yaitu uji korelasi sederhana dan sumbangan efektif (SE). Penelitian ini menghasilkan kesimpulan bahwa terdapat hubungan positif yang signifikan antara intensitas belajar dengan hasil belajar PPKn siswa kelas IV SD dengan tingkat korelasi sedang yaitu 0,371 dan sumbangan variabel intensitas belajar dengan hasil belajar PPKn siswa kelas IV SD yaitu $13,7 \%$. Berdasarkan hasil penelitian tersebut dapat disimpulkan bahwa terdapat hubungan positif yang signifikan antara intensitas belajar dengan hasil belajar PPKn siswa kelas IV SD Negeri se-Kecamatan Kebumen tahun ajaran 2020/2021.
\end{abstract}

Kata kunci: Intensitas Belajar, Hasil Belajar, PPKn

This work is licensed under a Creative Commons Attribution-ShareAlike 4.0 International License. 


\section{PENDAHULUAN}

Menurut Maryam, S (2013: 1) Pendidikan Pancasila dan Kewarganegaraan (PPKn) merupakan mata pelajaran sosial yang bertujuan untuk membentuk atau membina warga negara yang baik, yaitu warga negara yang tahu, mau dan mampu berbuat baik sesuai nilai - nilai Pancasila. Mata pelajaran Pendidikan Pancasila dan Kewarganegaraan adalah mata pelajaran wajib yang selalu diajarkan oleh guru dan dosen dari mulai SD sampai bangku perkuliahan. Materi dari setiap bab pada mata pelajaran Pendidikan Pancasila dan Kewarganegaraan ini harus diajarkan dan dipahami dengan baik serta harus berkonsentrasi penuh agar dapat mengingat setiap hal yang diajarkan guru karena Pendidikan Pancasila dan Kewarganegaraan merupakan salah satu mata pelajaran hafalan.

Berdasarkan hasil wawancara pada tanggal 12-13 Oktober 2020 dengan beberapa guru kelas IV di SDN 4 Kutosari, SDN 1 Tamanwinangun, SDN 5 Kutosari, rata - rata anak kelas IV SD sulit memahami materi PPKn yang diajarkan guru dan tidak ingin menghafal materi PPKn yang banyak akhirnya hasil belajar PPKn siswa kelas IV SD banyak yang kurang bagus karena dari 3 sd tersebut nilai rata- rata siswa SDN 4 Kutosari yaitu 78, SDN 1 Tamanwinangun yaitu 73, SDN 5 Kutosari yaitu 73. Di lingkungan sekolah, PPKn dianggap ilmu yang sukar dan sulit dipahami. PPKn adalah pelajaran formal yang berupa sejarah masa lampau, perkembangan sosial budaya, perkembangan teknologi, tata cara hidup bersosial, serta peraturan kenegaraan. Begitu luasnya materi PPKn menyebabkan anak sulit untuk diajak berfikir kritis dan kreatif dalam menyikapi masalah yang berbeda. Sementara anak usia sekolah dasar tahap berfikir mereka masih belum formal, karena mereka baru berada pada tahap operasional konkret. Apa yang dianggap logis, jelas dan dapat dipelajari bagi orang dewasa, kadang - kadang merupakan hal yang tidak masuk akal dan membingungkan bagi siswa. Akibatnya banyak siswa yang tidak memahami konsep PPKn. Banyak siswa khususnya di jenjang sekolah dasar yang kurang senang dengan mata pelajaran ini dan siswa kurang berminat serta cepat bosan dikarenakan harus banyak menghafal materinya, hal ini dapat mempengaruhi hasil belajar mereka terutama dalam mata pelajaran PPKn.

Supratiknya (2012 : 5) mengemukakan bahwa hasil belajar yang menjadi objek penilaian kelas berupa kemampuan-kemampuan baru yang diperoleh siswa setelah mereka mengikuti proses belajar mengajar tentang mata pelajaran tertentu. Pendapat tersebut senada dengan yang dikemukakan oleh Mahajan \& Singh (2017: 65) mengenai definisi hasil belajar adalah alat penuntun yang membimbing siswa untuk mengetahui hasil yang diinginkan berdasarkan pelajaran yang sudah diikuti. Hasil belajar siswa tergantung pada minat siswa terhadap pelajaran tersebut dan intensitas belajar siswa. Seperti yang diungkapkan Djaali (Syarifuddin, 2011: 215) bahwa terdapat faktor yang mempengaruhi belajar yakni motivasi; sikap; minat; intensitas belajar; konsep diri.

Intensitas belajar siswa merupakan salah satu faktor yang mempengaruhi belajar siswa. Menurut Melda (2015 : 17) intensitas belajar adalah realitas dari motivasi dalam rangka mencapai tujuan yang diharapkan yaitu peningkatan prestasi, sebab seseorang melakukan usaha dengan penuh semangat karena adanya motivasi sebagai pendorong pencapaian prestasi. Proses kegiatan belajar siswa memiliki intensitas yang berbeda beda. Belajar tidak harus dilakukan dalam waktu yang lama, yang terpenting belajar harus dilakukan secara rutin setiap hari, sehingga dengan rutinitas tersebut belajar menjadi kebiasaan yang dilakukan oleh siswa. Keteraturan belajar, penggunaan dan pembagian waktu belajar apabila dilaksanakan dengan baik setiap hari, maka akan menjadi suatu kebiasaan belajar yang baik. Dengan mengatur waktu secara efisien dan 
efektif individu akan memperoleh beberapa keuntungan misalnya dapat mengatur kegiatan dengan baik sehingga lebih banyak waktu yang dikerjakan.

Berdasarkan uraian di atas, kondisi siswa kelas IV SD mengenai keterkaitan dengan intensitas belajar sangat berpengaruh terhadap hasil belajar siswa khususnya PPKn dan karena kondisi sekarang yang mengharuskan siswa hanya mengikuti pembelajaran bersama guru selama beberapa jam saja serta siswa harus belajar sendiri di rumah menyebabkan waktu untuk memahami pembelajaran bagi siswa masih kurang. Menurut Janah (2018: 17-19) pengaturan waktu untuk jam belajar siswa yang baik adalah 7 jam, jika kurang dari itu, maka siswa dapat dikatakan intensitas belajarnya kurang dan membuat hasil belajar menjadi tidak memuaskan. Hal tersebut membuat penting kiranya dilakukan penelitian untuk mengetahui ada tidaknya hubungan antara intensitas belajar terhadap hasil belajar PPKn dan menghitung besarnya sumbangan intensitas belajar dengan hasil belajar PPKn siswa kelas yang dimiliki siswa kelas IV SD di Kecamatan Kebumen melalui penelitian kuantitatif dengan judul "Hubungan Intensitas belajar dengan hasil belajar PPKn siswa Kelas IV SD Negeri se-Kecamatan Kebumen Tahun Ajaran 2020/2021".

Tujuan penelitian ini adalah: (1) membuktikan ada tidaknya hubungan antara intensitas belajar dengan hasil belajar PPKn siswa kelas IV SDN se-Kecamatan Kebumen tahun ajaran 2020/2021; (2) menghitung besarnya sumbangan intensitas belajar dengan hasil belajar PPKn siswa kelas IV SDN se-Kecamatan Kebumen tahun ajaran 2020/2021.

\section{METODE}

Penelitian ini merupakan penelitian kuantitatif dengan metode korelasi. Populasi penelitian ini adalah seluruh siswa kelas IV di 56 SDN se-Kecamatan Kebumen tahun ajaran 2020/2021 yang berjumlah 1.400 siswa. Sampel pada penelitian ini berjumlah 347 siswa kelas IV di tiga belas SDN se-Kecamatan Kebumen yang dipilih secara acak dengan teknik cluster random sampling. Pengambilan sampel dengan cara cluster random sampling adalah dengan melakukan randomisasi terhadap kelompok (sekolah), bukan terhadap subjek secara individual. Sekolah yang digunakan pada penelitian ini yaitu SDN 2 Panjer, SDN 4 Kutosari, SDN 5 Kutosari, SDN 2 Bumirejo, SDN Gesikan, SDN Mengkowo, SDN 1 Tanahsari, SDN 1 Tamanwinangun, SDN 1 Gemeksekti, SDN Jemur, SDN 3 Wonosari, SDN 6 Panjer, SDN 2 Adikarso.

Teknik pengumpulan data pada penelitian ini menggunakan angket dan tes. Teknik angket digunakan untuk mengumpulkan data intensitas belajar dan tes digunakan untuk mengumpulkan data hasil belajar PPKn siswa kelas IV SD. Uji prasyarat analisis data yang digunakan yaitu uji normalitas dan uji linieritas. Analisis data yang digunakan yaitu korelasi sederhana dan sumbangan efektif (SE) dengan taraf signifikansi $5 \%$.

\section{HASIL DAN PEMBAHASAN}

Penelitian ini dilakukan dengan memberikan angket intensitas belajar dan tes materi PPKn kepada siswa kelas IV di tiga belas SDN di Kecamatan Kebumen. Angket ini berisi tentang indikator yang berhubungan dengan intensitas belajar sehingga dapat mengukur tinggi rendahnya intensitas belajar yang dimiliki siswa kelas IV SD. Tes ini berisi soal-soal yang memuat indikator materi PPKn kelas IV SD sehingga dapat mengukur tinggi rendahnya hasil belajar PPKn siswa kelas IV SD. Prasyarat data terpenuhi yaitu data berasal dari populasi berdistribusi normal dan terdapat hubungan linear antara intensitas belajar dan hasil belajar PPKn siswa kelas IV SD. Data hasil penelitian berasal dari data berdistribusi normal yang ditunjukkan dengan nilai 
signifikansi intensitas belajar 0,077 dan hasil belajar PPKn siswa kelas IV SD yakni 0,067 . Kedua nilai signifikansi data menunjukkan nilai $>0,05$ sehingga data tersebut berasal dari populasi berdistribusi normal. Data dikatakan terdapat hubungan linear antara variabel $X$ dan $Y$ jika $p$ value Deviation from Linearity $>0,05$. Nilai $p$ value Deviation from Linearity yaitu 0,455 >0,05 sehingga terdapat hubungan linear antara intensitas belajar dengan hasil belajar PPKn siswa kelas IV SD.

Korelasi antara intensitas belajar dengan hasil belajar PPKn siswa kelas IV SD diuji menggunakan uji korelasi pearson product moment. Uji Korelasi menggunakan bantuan aplikasi SPSS versi21.

Hipotesis yang digunakan adalah $\mathrm{H}_{0}=$ tidak ada hubungan positif antara intensitas belajar dengan hasil belajar PPKn siswa kelas IV SD dan $\mathrm{H}_{1}=$ ada hubungan positif antara intensitas belajar dengan hasil belajar PPKn siswa kelas IV SD.

Tabel 1 Distribusi Frekuensi Intensitas Belajar dan Hasil Belajar PPKn

\begin{tabular}{lcccc}
\hline & \multicolumn{2}{c}{ Intensitas Belajar } & \multicolumn{2}{c}{ Hasil Belajar PPKn } \\
\cline { 2 - 5 } No. & Interval & Frekuensi & Interval & Frekuensi \\
\hline 1. & $64-66$ & 9 & $36-40$ & 8 \\
2. & $67-69$ & 15 & $41-45$ & 15 \\
3. & $70-72$ & 19 & $46-50$ & 21 \\
4. & $73-75$ & 33 & $51-55$ & 40 \\
5. & $76-78$ & 49 & $56-60$ & 39 \\
6. & $79-81$ & 68 & $61-65$ & 64 \\
7. & $82-84$ & 52 & $66-70$ & 57 \\
8. & $85-87$ & 46 & $71-75$ & 46 \\
9. & $88-90$ & 28 & $76-80$ & 33 \\
10. & $91-93$ & 18 & $81-85$ & 15 \\
11. & $94-97$ & 10 & $85-89$ & 9 \\
\hline & Total & 347 & & 347 \\
\hline
\end{tabular}

Tabel 2 Hasil Analisis Korelasi Intensitas Belajar dengan Hasil Belajar PPKn Siswa Kelas IV SD

\begin{tabular}{|c|c|c|c|c|c|c|c|}
\hline & & \multicolumn{6}{|c|}{ Correlations } \\
\hline \multicolumn{8}{|c|}{ ANOVA Table } \\
\hline & & & $\begin{array}{l}\text { Sum of } \\
\text { Squares }\end{array}$ & $d f$ & $\begin{array}{l}\text { Mean } \\
\text { Square }\end{array}$ & $F$ & Sig. \\
\hline \multirow{8}{*}{$\begin{array}{l}\text { Hasil Belajar } \\
\text { PPKn * } \\
\text { Intensitas } \\
\text { belajar }\end{array}$} & Between & (Combined) & 10718,00 & 33 & 324,78 & 2,65 &, 000 \\
\hline & Groups & & 1 & & 8 & 0 & \\
\hline & & Linearity & 6753,433 & 1 & $\begin{array}{r}6753,4 \\
33\end{array}$ & $\begin{array}{r}55,1 \\
07\end{array}$ &, 000 \\
\hline & & Deviation from & 3964,569 & 32 & 123,89 & 1,01 & , 455 \\
\hline & & Linearity & & & 3 & 1 & \\
\hline & Within $G$ & oups & 38358,54 & 313 & 122,55 & & \\
\hline & & & 0 & & 1 & & \\
\hline & Total & & $\begin{array}{r}49076,54 \\
2\end{array}$ & 346 & & & \\
\hline
\end{tabular}

**. Correlation is significant at the 0.01 level (1-tailed).

Berdasarkan analisis data menggunakan uji korelasi pearson product moment, 
diketahui bahwa terdapat hubungan positif yang signifikan antara intensitas belajar dengan hasil belajar PPKn siswa kelas IV SD dengan koefisien korelasi sebesar 0,371 dan Sig. (1-tailed) yaitu 0,000 ( $p$ value $<0,05$ ). Nilai 0,05 adalah taraf signifikansi yang digunakan pada penelitian ini. Sesuai dengan hasil uji korelasi tersebut, maka hipotesis yang menyatakan bahwa terdapat terdapat hubungan yang positif dan signifikan antara intensitas belajar dengan hasil belajar PPKn siswa kelas IV SDN seKecamatan Kebumen tahun ajaran 2020/2021 dapat diterima. Hasil analisis koefisien korelasi antara variabel intensitas belajar dan hasil belajar PPKn siswa kelas IV SD yaitu 0,371 . Berdasarkan pendapat Pranoto (2016: 6) mengenai pedoman interpretasi terhadap koefisien korelasi menyatakan bahwa koefisien korelasi pada penelitian ini yaitu 0,371 berada pada tingkat hubungan sedang.

Sesuai hasil perhitungan sumbangan intensitas belajar dengan hasil belajar PPKn siswa kelas IV SD sebesar 13,7\% dan sisanya sebesar $86,3 \%$ dipengaruhi oleh faktor lain. Penelitian ini juga mendapatkan hasil yang hampir sama hasil penelitian terdahulu yang dilakukan oleh Wulandari, R. (2013: 7) dengan mendapatkan kontribusi sumbangan efektif intensitas belajar sebesar $11,93 \%$ saja. Menurut Lufri, dkk (2020: 313) sumbangan efektif kecil dapat disebabkan karena suatu variabel bebas yang berada bersama-sama dengan variabel bebas yang lain dalam persamaan regresi, peranannya sebagai prediktor variabel terikat dapat ditekan oleh variabel lain. Hal ini dapat dipahami bahwa masih banyak faktor lain, disamping faktor intensitas belajar yang dapat memengaruhi hasil belajar.

Berdasarkan penelitian dan perhitungan yang telah dilakukan, keterkaitan hasil belajar PPKn siswa kelas IV SD dengan intensitas belajar sangat berpengaruh, sesuai pendapat Pumadi (2016: 82) intensitas belajar sangat berperan penting terhadap pencapaian kemampuan hasil belajar siswa, tanpa adanya rutinitas belajar khususnya PPKn maka siswa menjadi kurang teratur dalam belajar yang banyak membutuhkan konsentrasi dan daya ingat tinggi. Menurut Janah (2018: 17-19) pengaturan jam belajar siswa yang baik adalah 7 jam, jika kurang maka siswa dikatakan intensitas belajarnya kurang dan membuat hasil belajar tidak memuaskan. Sesuai penelitian dengan siswa kelas IV sd se-Kecamatan Kebumen, jumlah waktu belajar siswa berpengaruh terhadap hasil belajar khususnya PPKn. Maka, dapat diketahui bahwa intensitas belajar memiliki hubungan yang positif dengan hasil belajar PPKn siswa kelas IV SD. Oleh karena itu, dapat dikatakan bahwa semakin tinggi intensitas belajar siswa maka semakin tinggi pula hasil belajar PPKn siswa. Begitu juga sebaliknya, semakin rendah intensitas belajar siswa maka akan semakin rendah pula hasil belajar PPKn siswa. Hasil penelitian ini sesuai dengan penelitian yang dilakukan oleh Fitriyani (2019: 43) yang menyatakan bahwa terdapat ada hubungan yang positif dan signifikan antara intensitas belajar dengan prestasi belajar siswa yang dibuktikan dengan koefisien korelasi sebesar 0,544. Maka intensitas belajar mempunyai hubungan dengan hasil belajar siswa.Selain itu hasil penelitian ini juga sesuai dengan penelitian yang dilakukan oleh Riyandiarto (2017: 5) yang menyatakan bahwa terdapat ada hubungan antara intensitas belajar dengan hasil belajar siswa yang ditunjukkan dengan koefisien korelasi sebesar 0,355. Dengan kata lain, semakin tinggi intensitas belajar siswa maka hasil belajar akan meningkat. Penelitian ini penting diadakan peneliti dikarenakan penelitian sebelumnya mengambil sampel hanya 1 sekolah dan sekarang mengambil sampel siswa kelas IV di 13 sd se-Kecamatan Kebumen.

Hasil perhitungan sumbangan efektif pada variabel intensitas belajar dan hasil belajar PPKn siswa kelas IV SD didapatkan hasil sebesar 13,7\%, artinya kintensitas belajar yang dimiliki siswa dapat berperan dalam meningkatkan khasil belajar PPKn siswa kelas IV SD sebesar $13,7 \%$ dan sisanya sebesar $86,3 \%$ dipengaruhi oleh faktor lain seperti sikap, minat, konsep diri pada siswa. 


\section{SIMPULAN}

Berdasarkan hasil penelitian dan pembahasan yang telah diuraikan, maka dapat disimpulkan bahwa: (1) intensitas belajar memiliki hubungan yang positif dan signifikan dengan hasil belajar PPKn siswa kelas IV SD Negeri se-Kecamatan Kebumen tahun ajaran 2020/2021; (2) besar sumbangan variabel intensitas belajar terhadap hasil belajar PPKn yaitu 13,7\%.

Berdasarkan simpulan yang telah dipaparkan, peneliti memberikan beberapa saran: (1) bagi guru, memberikan dorongan kepada siswa untuk giat dalam belajar secara intens agar hasil belajar menjadi lebih maksimal; (2) bagi sekolah, diharapkan dapat berkoordinasi dengan guru untuk meningkatkan kualitas pembelajaran; (3) bagi wali siswa, diharapkan dapat memberikan motivasi dan membimbing siswa agar mau belajar secara berulang-ulang sesuai jadwal belajar sehingga intensitas belajar siswa meningkat; (4) bagi peneliti selanjutnya depan yang akan meneliti ulang mengenai variabel intensitas belajar dan hasil belajar, alangkah baiknya untuk menambah sumber referensi yang lebih banyak lagi dan mengganti tempat dan objek penelitian agar penelitian selanjutnya menjadi lebih baik lagi.

\section{DAFTAR PUSTAKA}

Fitriyani. (2019). Hubungan Minat Belajar dan Intensitas Belajar Dengan Prestasi Belajar Matematika Siswa Kelas VII SMP Negeri 1 Karanganom. Mathematics Education Journal, Volume 1 Nomor 1, Mei 2019.

Janah, N.L.U. (2018). Pengaruh Intensitas Belajar Dan Gaya Belajar Terhadap Prestasi Belajar Siswa di MIN 14 Kabupaten Blitar. Skripsi. IAIN Tulungagung.

Lufri, dkk. (2020). Metodologi Pembelajaran: Strategi, Pendekatan, Model, Metode Pembelajaran. Malang: CV. IRDH.

Mahajan, M \& Singh, M.K.S. (2017). Importance and Benefits of Learning Outcomes. OSR Journal Of Humanities And Social Science (IOSR - JHSS) Volume 22, Issue 3, Ver. V (March. 2017) PP 65-67 e-ISSN: 2279 - 0837, p - ISSN: 2279 0845.

Maryam, S. (2013). Penggunaan Model Picture And Picture untuk Meningkatkan Aktivitas Belajar Siswa Pada Pelajaran PKN Materi Pokok Budaya Indonesia yang Dipentaskan di Luar Negeri di Kelas IV SD Negeri 01 Blangjerango Gayo Lues Tahun Ajaran 2012/2013. Skripsi. Universitas Negeri Medan.

Melda. (2015). Pengaruh Media Massa Terhadap Intensitas Belajar Matematika Di Rumah Pada Siswa Kelas XI IPS MAN Palopo. Skripsi. IAIN Palopo.

Pranoto. (2016). Hubungan Penerapan Strategi Pembelajaran Dengan Prestasi Belajar Peserta Didik di LBB Primagama Kabupaten Lamongan. Jurnal J+PLUS UNESA Vol. 5 No. 1.

Pumadi, A. (2016). Hubungan Intensitas Belajar Terhadap Prestasi Belajar Fisika Siswa SMA. Jurnal Teknologi Pendidikan Volume 1 Nomor 2 Edisi Oktober 2016.

Riyandiarto. (2017). Hubungan Intensitas Belajar di Sekolah terhadap Hasil Belajar Matematika Siswa Kelas VIII. Jurnal MathGram Matematika Vol. 2 No. 1 April 2017.

Supratiknya, A. (2012). Penilaian Hasil Belajar dengan Teknik Nontes. Yogyakarta: Universitas Sanata Darma.

Syarifudin, A. (2011). Penerapan Model Pembelajaran Cooperative Belajar dan Faktor Faktor yang Mempengaruhinya. Jurnal TA'DIB, Vol. XVI, No. 01, Edisi Juni 2011. 
Wulandari, R. (2013). Hasil Belajar Siswa Ditinjau Dari Intensitas Belajar Dan Lingkungan Sosial Pada Mata Pelajaran Akuntansi Siswa Kelas XI IPS SMS Negeri 1 Nogosari Tahun Ajaran 2012/2013. Skripsi Thesis, Universitas Muhammadiyah Surakarta. 